\title{
24. GEOMAGNETIC-FIELD VARIATIONS RECORDED WITHIN DRILL PIPE AT SITE 865: IMPLICATIONS FOR PALEOMAGNETIC STUDIES ${ }^{1}$
}

\author{
Yoshifumi Nogi, ${ }^{2}$ John A. Tarduno, ${ }^{3}$ and William W. Sager ${ }^{4}$
}

\begin{abstract}
In this study, we measured the magnetic field within the drill string with a wireline magnetometer log and estimated the effect that this magnetic-field might have on paleomagnetic core samples. Sharp decreases in the vertical magnetic-field component and sharp increases in the horizontal component were observed at approximately $10-\mathrm{m}$ intervals, corresponding to the pipe joints. Induced magnetization by the greater thicknesses of iron at these connection points apparently causes the magnetic-field variations.

The bottom-hole assembly of the drill string was dominated by induced magnetization and possibly was affected by permanent magnetization. In general, the magnetic-field throughout most of the drill pipe and bottom-hole assembly is only two to five times greater than the Earth's magnetic field at Site 865 and so is not likely to affect paleomagnetic samples. However, the magnetometer's vertical sensor became saturated in a downward direction between 344 and $356 \mathrm{~m}$ below the rig floor at Site 865 , suggesting negative inclination of a strong permanent magnetization of two pipes within this zone. Such a strong magnetic field is a likely cause of remagnetization of core samples.
\end{abstract}

\section{INTRODUCTION}

Paleomagnetic studies have an important role in the scientific goals of the Ocean Drilling Program. The fundamental data of such studies are the inclination, declination, and intensity of the natural remanent magnetizations (NRM) of cored sediments and rocks. Usually, the magnetization of geological significance is that acquired at the time of rock or sediment formation, that is, the primary magnetization, and part of the challenge of paleomagnetic studies is to remove spurious magnetizations that mask the primary component.

Often paleomagnetists working on ODP core material have found a significant secondary magnetization with a nearly vertical direction; this has been attributed to large magnetic fields within the drill pipes (e.g., Kikawa and Pariso, 1991), through which core samples must pass on their way to the surface. Nevertheless, there has been no solid evidence that the drill string is actually the culprit. During Leg 143, magnetic logs were taken with the Japanese downhole three-component magnetometer (JDTCM), and data were incidentally obtained within the drill string. In this study, we describe the magnitude and character of the magnetic field within the drill string and examine its implications.

\section{JAPANESE DOWNHOLE THREE-COMPONENT MAGNETOMETER}

The JDTCM is a self-contained three-component fluxgate magnetometer designed for downhole magnetic field measurement in ODP holes. Magnetic-field data are recorded in an internal microprocessor from the time the instrument is deployed; thus, measurements are acquired from the rig floor to deployment depth. The resolution of the magnetic field is changeable; settings are $1.02,1.36$, and $2.03 \mathrm{nT}$. The measurement range of the magnetic field of each axis of the magnetometer is $\pm 65,519 \mathrm{nT}$ for the lowest sensitivity. The sampling inter$\mathrm{val}$ is $3 \mathrm{~s}$.

${ }^{1}$ Winterer, E.L., Sager, W.W., Firth, J.V., and Sinton, J.M. (Eds.), 1995, Proc, ODP, Sci. Results, 143: College Station, TX (Ocean Drilling Program).

${ }^{2}$ Geochemical Research Department, Meteorological Research Institute, Tsukuba, Ibaraki 305. Japan.

${ }^{3}$ Department of Earth and Environmental Sciences, University of Rochester, Rochester, NY 14627, U.S.A.

${ }^{4}$ Department of Oceanography, Texas A\&M University, College Station, TX 77843,
Magnetic-field variations in the drill pipe at Site 865 were recorded at the lowest sensitivity with a logging speed between 1440 and $2000 \mathrm{~m} / \mathrm{hr}$, corresponding to a sampling interval between 1.2 and $1.8 \mathrm{~m}$. Although magnetometer logs were also taken at Sites 866 and 869 , those from Site 865 are best for showing the effect of the drill string because of the lowest sensitivity scale and slow logging speed.

\section{DATA AND DATA PROCESSING}

The raw data of horizontal and vertical components of the magnetic field between 0 and 1850 meter below rig floor (mbrf) at Site $865\left(18^{\circ} 26.410^{\prime} \mathrm{N}, 179^{\circ} 33.339^{\prime} \mathrm{W}\right)$ were used. Water depth of this site is $1518.4 \mathrm{~m}$. The section between about 0 and 1620 mbrf consists of the dill pipes and bottom of this section, between 1440 and $1620 \mathrm{mbrf}$, is the bottom-hole assembly (BHA). Below $1620 \mathrm{mbrf}$, the section corresponds to limestone without the drill pipes.

The inclination results from a single, homogeneous, cylindrical magnetized body, called the apparent inclination, are obtained from the ratio between the spatial differential of the vertical to the horizontal component of the magnetic field (Nogi et al., this volume). The apparent inclination within the drill pipe between 100 and $1400 \mathrm{mbrf}$ and in the BHA between 1510 and 1620 mbrf was calculated, using the spatial differentials of the horizontal and vertical magnetic field (except for the data that are out of the measurement range). The ratio between the spatial differential of the vertical to the horizontal component of the magnetic field was determined by linear regression.

The quality of data of the horizontal magnetic field is apparently degraded by the rapid tool rotation. Sharp, high-amplitude $(\sim 30,000$ nT) decreases in the horizontal magnetic field were observed within the weakly magnetized limestone and dolomite section at Site 865, where the logging cable speed was faster than $2000 \mathrm{~m} / \mathrm{hr}$ (Nogi et al., this volume). Similar decreases were not observed in the vertical component. Although the origin of the sharp decreases have not been identified, these variations seem to be caused by the abrupt change of the tool orientation owing to fast logging cable speed and the unstable hole conditions (Nogi et al., this volume). The logging cable speed within drill pipes is faster $(1440-2000 \mathrm{~m} / \mathrm{hr}$ ) than the usual logging speed $(<1000 \mathrm{~m} / \mathrm{hr})$. Because the tool rotation is considered to be derived from the wrench of the wireline cable, the tool rotation speed depends upon the logging cable speed. Therefore, horizontal magnetic field data are possibly affected by sharp decreases caused by the rapid tool rotation. 


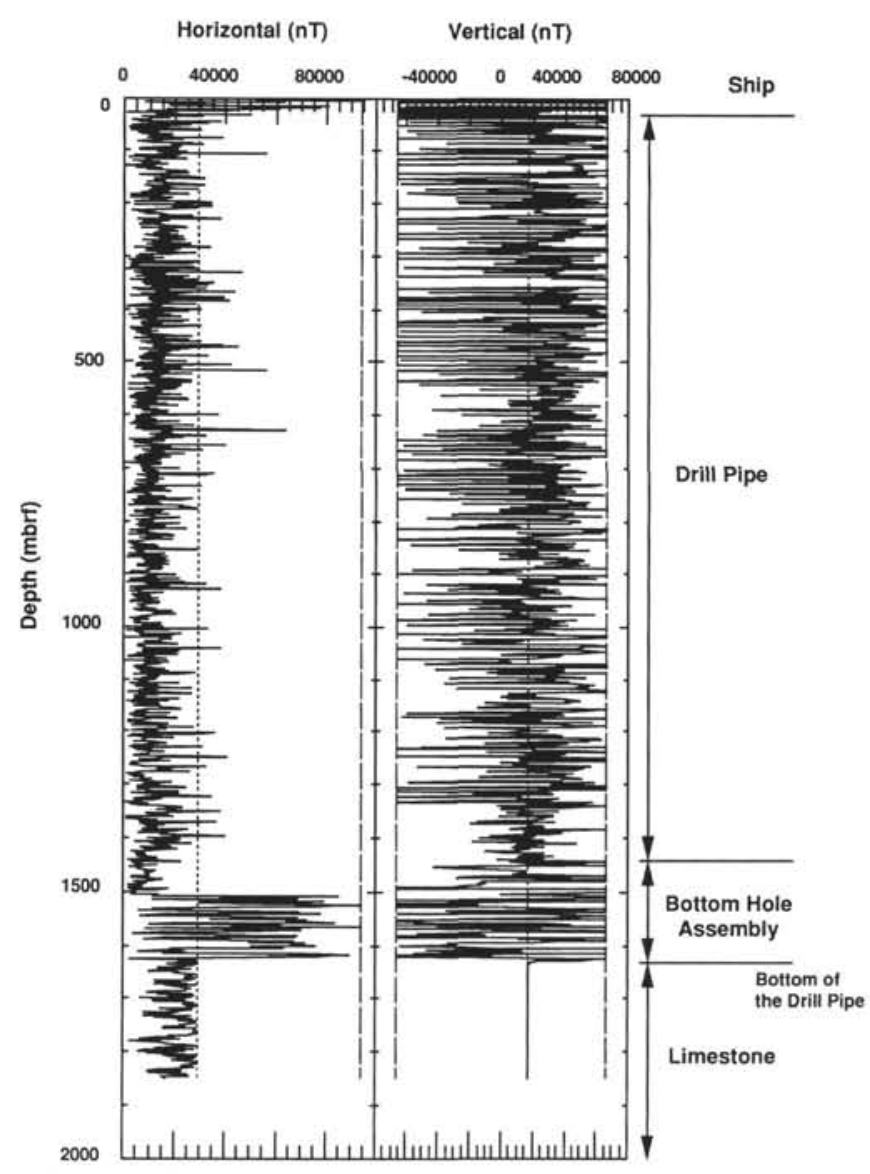

Figure 1. Horizontal and vertical components of magnetic-field variations in drill pipe between 0 and $1850 \mathrm{mbrf}$. Dotted and dashed lines show the Earth's field estimated at Site 865 and the measurement range of each component, respectively.

\section{RESULTS}

\section{Magnetic Field in Drill Pipe}

Figure 1 shows horizontal and vertical components of the magnetic-field between 0 and $1850 \mathrm{mbrf}$. The present magnetic field used here (dotted line in Fig. 1) is that estimated within limestone section between 700 and 800 mbsf at Site 865 by the JDTCM (Nogi et al., this volume). Magnetic-field variations above about 20 mbrf seem to be affected by ship's magnetization. Magnetic-field variations caused by the drill pipe are observed between about 100 and $1620 \mathrm{mbrf}$, but the character between about 1440 and $1620 \mathrm{mbrf}$ is different from that above because of the BHA. Sharp decreases only in the horizontal component, probably caused by tool rotation, are observed within the limestone section, below $1620 \mathrm{mbsf}$. In contrast, the vertical magnetic field below $1620 \mathrm{mbsf}$ is smooth and nearly coincides with the present magnetic field estimated by the JDTCM.

Sharp spikes are observed in the record, particularly in the vertical component (Fig. 1). A closer look shows that most of the spikes are decreases in the field (Fig. 2). The interval between spikes is almost $10 \mathrm{~m}$, which is the same as the length of one joint of pipe (average $9.65 \mathrm{~m}$ ). Horizontal component spikes were observed, but their amplitudes seem to be smaller than those of the vertical component. The level of the horizontal magnetic field component within the drill pipe is significantly lower than that of the ambient magnetic field. The shape of the spikes, a sharp decrease in the vertical component and an increase in the horizontal component, indicate that the drill pipe exhibits normal polarity magnetization.

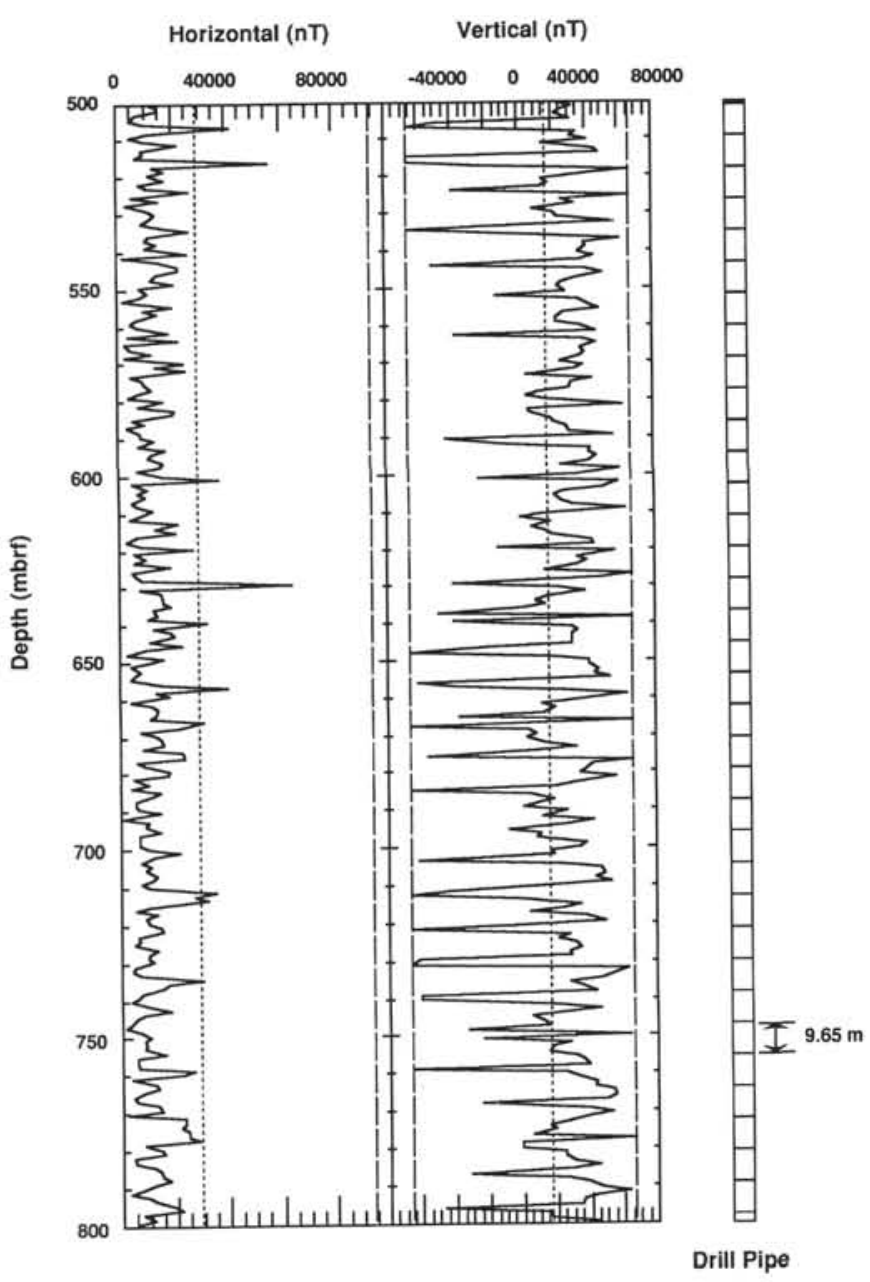

Figure 2. Horizontal and vertical components of magnetic-field variations in drill pipe between 500 and 800 mbrf, together with a schematic drawing of the drill pipe. Dotted and dashed lines are the same as those in Figure 1.

A more detailed view of magnetic-field variations between 500 and $800 \mathrm{mbrf}$ is shown in Figure 2. One can see more clearly the regularity and spacing of spikes that suggest they result from pipe-joint connections. The locations of the pipe-joint connections were based on the drill-pipe connection record at Site 865. Pipe joints are thicker than the rest of the drill string; therefore, the greater thicknesses of metal may cause the observed spikes owing to their greater magnetic field. Although some spikes are out of the magnetometer's sensitivity range, the amplitudes of most spikes are less than 80,000 nT (i.e., two times the ambient Earth's field). If the saturated peaks are linearly extrapolated, their amplitude peaks are less than $120,000 \mathrm{nT}$, about three times greater than Earth's magnetic field. Sharp increases in the horizontal component of the magnetic field also coincide with the connections between drill-pipe joints, but their amplitudes seem to be smaller than those of the vertical component spikes. Horizontal component data are probably adversely affected by the tool rotation. This is probably the reason that the horizontal spikes do not have as regular a spacing and signature as those of the vertical component. The maximum horizontal component spike is about $80,000 \mathrm{nT}$.

Between 344 and 356 mbrf, the vertical component is unusually strong and out of the measurement range (Fig. 3). There is no significant change in the horizontal component of the magnetic field within this zone. This behavior is not observed in the magnetic-field variation at other places in the drill pipe. Two drill pipes and joints are 


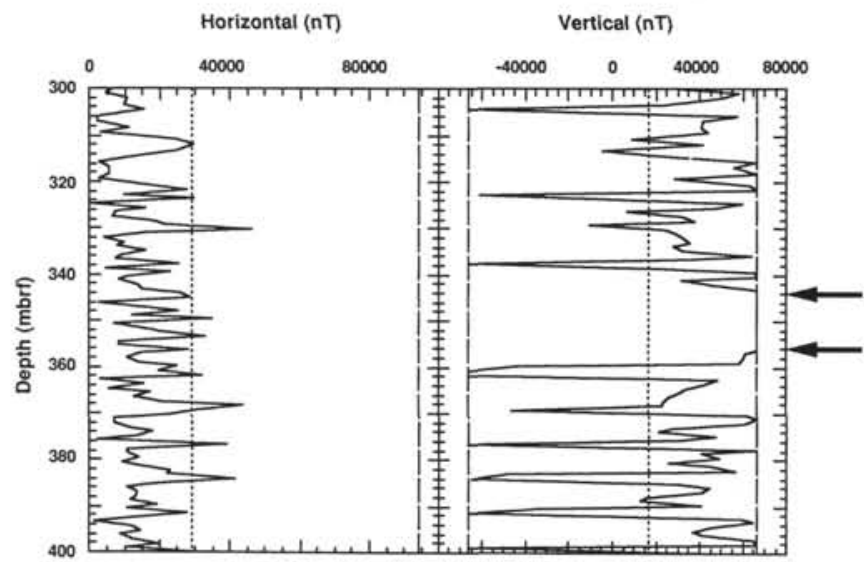

Figure 3. Horizontal and vertical components of magnetic-field variations in drill pipe between 300 and 400 mbrf. Dotted and dashed lines are the same as those in Figure 1. Arrows indicate the zone where the variation of the vertical component is completely saturated downward.

contained within this zone, suggesting that these drill pipes, between 344 and 356 mbrf, have higher magnetizations than the others.

The magnetic variations between 1440 and 1625 mbrf have a different character owing to the BHA (Fig. 4). Almost all the peaks in the magnetic-field variation of the vertical component are out of the measurement range. At about $1500 \mathrm{mbsf}$, a significant saturated positive vertical component of the magnetic-field variation is observed. The amplitude of this variation is estimated at almost $220,000 \mathrm{nT}$, using linear extrapolation, which is about five times larger than that of the present-day magnetic field. Amplitudes of sharp increases in the magnetic-field variations of the horizontal component are also larger than those of the drill pipe, at about $80,000 \mathrm{nT}$. A few peaks in the horizontal component also seem to be out of the measurement range.

A sharp decrease in the vertical component and a sharp increase in the horizontal component mark the boundaries of segments of the BHA. This indicates that each segment produces magnetic-field variations in spite of having the same inner and outer diameter. Moreover, four sharp decreases in the magnetic-field vertical component were observed between about 1440 and 1490 mbrf, implying variations within one long segment of the BHA (Fig. 4). These four decreases imply the presence of two magnetic boundaries inside the one long part of the BHA. These variations can be explained by assuming that each part of the BHA has a different intensity and/or polarity of magnetization, implying that heterogeneous magnetization within the BHA may cause those variations.

The apparent inclination within the drill pipe between 100 and $1400 \mathrm{mbrf}$, and in the BHA between 1510 and $1620 \mathrm{mbrf}$, was obtained by linear regression (Fig. 5). For 100 to $1400 \mathrm{mbsf}$, the correlation between the spatial differential of the horizontal and vertical components of the magnetic field is not good, but the calculated apparent inclination from that gradient is $19.5^{\circ}$. On the other hand, the correlation between horizontal and vertical component differentials from the BHA is better. The apparent inclination given by the $\mathrm{BHA}$ is $22.2^{\circ}$. The negative gradient reflects a normal magnetization acquired in the Northern Hemisphere, because vertical and horizontal magnetic fields in the hole caused by a Northern Hemisphere normal magnetization vary in the opposite sense, assuming a homogeneous, cylindrical magnetized body (Nogi et al., this volume). The apparent inclination given by the BHA is slightly shallower than the ambient field inclination of $30^{\circ}$ at Site 865 .

\section{Model Calculation}

Horizontal and vertical components of the drill-pipe magnetic field were simulated by a stack of cylindrical magnetized bodies

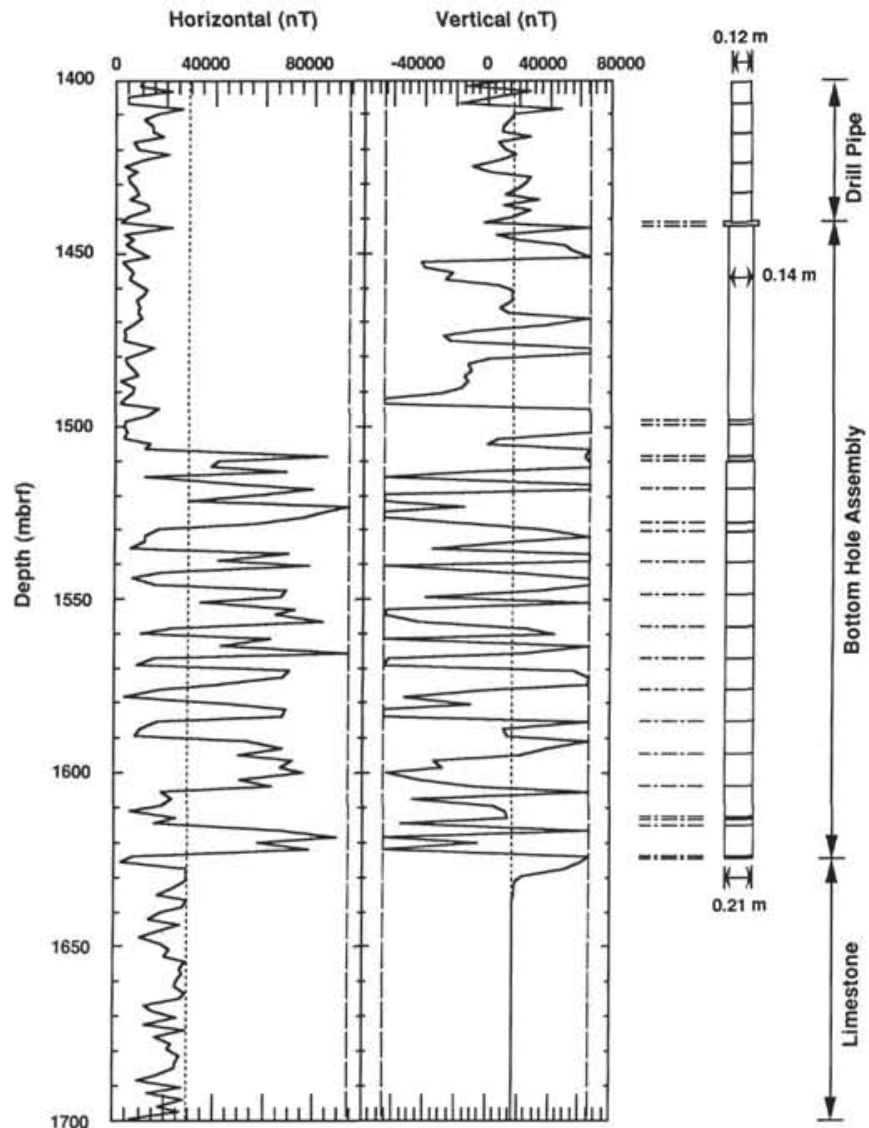

Figure 4. Horizontal and vertical components of magnetic-field variations in drill pipe between 1400 and $1700 \mathrm{mbrf}$, together with a schematic drawing of drill pipe. Dotted and dashed lines are the same as those in Figure 1. Dashdotted lines show the segment boundaries of the BHA.

(Hamano and Kinoshita, 1990). The configuration of the model was based on the geometry of the drill pipe and its component joints as given in Table 1. The apparent inclination of the pipe was used as inclination of the magnetization, and the intensity of magnetization was assumed to be homogeneous, assuming an induced magnetization under the geomagnetic field. We used an intensity of $1 \mathrm{~A} / \mathrm{m}$ for convenience, because the amplitudes of magnetic variations are proportional to the intensity of the magnetization. The "zero level" of the magnetic field in the model calculation corresponds to the level of the ambient magnetic field at the site.

Magnetic-field data were calculated every $1 \mathrm{~m}$, similar to the observation interval for the drill pipe. If the calculated data interval is taken less than $1 \mathrm{~m}$, the horizontal and vertical component magnetic field variations become more symmetric and peaks of each component have the same amplitudes. Asymmetric features in the horizontal and vertical component variations and alternating amplitudes of the peaks in the model result from the calculated data interval.

Modeled magnetic variations are similar to those obtained from the logs (Fig. 6). The amplitude of negative peaks in the vertical component is about $700 \mathrm{nT}$ relative to the intensity of $20 \mathrm{~A} / \mathrm{m}$. Therefore, the intensity of the drill pipe magnetization is estimated at about $2200 \mathrm{~A} / \mathrm{m}$ from the observed amplitudes, although this estimate depends on the inclination of the magnetization. Assuming an inclination of $90^{\circ}$, for example, the peak amplitudes are large, about 2000 $\mathrm{nT}$, relative to the intensity of $20 \mathrm{~A} / \mathrm{m}$. This implies a possible factor of three error in the magnetization estimate.

The level of the observed horizontal component relative to the ambient magnetic field, appeared to be slightly lower than that reproduced by the model calculation. Sharp increases in the magnetic-field 
Table 1. Parameters for the model.

\begin{tabular}{lcccc}
\hline & $\begin{array}{c}\text { Inner } \\
\text { diameter } \\
(\mathrm{m})\end{array}$ & $\begin{array}{c}\text { Outer } \\
\text { diameter } \\
(\mathrm{m})\end{array}$ & $\begin{array}{c}\text { Length } \\
(\mathrm{m})\end{array}$ & $\begin{array}{c}\text { Interval } \\
(\mathrm{m})\end{array}$ \\
\hline Drill pipe: & 0.1 & 0.12 & 2000 & - \\
Joint: & 0.12 & 0.18 & 0.45 & 9.2 \\
\hline
\end{tabular}

variations in the horizontal component show an amplitude of about $1000 \mathrm{nT}$, somewhat larger than that of the observed sharp peaks of the vertical component. However, if a steeper inclination is employed for the model to reduce the amplitude of the horizontal magnetic field variation, the horizontal magnetic field varies around zero and the lower level of the horizontal component of the magnetic field with respect to the zero cannot be produced. This also suggests that the horizontal magnetic field variations are affected by the rapid tool rotation.

Model calculations for the BHA were not made, as magnetic-field variations in the BHA cannot be calculated from the simple model because of their complicated features. Their magnetic-field variations possibly are caused by heterogeneous magnetization of the component parts of the BHA, not by a change of thickness or diameter.

\section{DISCUSSION}

Induced magnetizations appear to be the main source of magneticfield variations within the drill pipe at Site 865. Magnetic-field variations from a model calculated with induced magnetization agree well with those observed in the drill pipe. The model calculation suggests further that the joints, where there is thicker drill pipes, cause most of the magnetic variations observed. Moreover, magnetic-field variations and apparent inclination suggest that magnetizations of most of the drill pipes originated in the Northern Hemisphere during a normal chron. It is difficult to accept that all drill pipe would have almost the same permanent magnetization that originated in the Northern Hemisphere during a normal chron, because more complicated magneticfield variations would be expected if a permanent magnetization of the pipe were significant.

The drill pipe is made of iron, and its surface is oxidized. Magnetite, which is one of the major iron oxides, has a susceptibility value of about 3 SI units (Dunlop, 1986). This suggests that the magnetization induced by magnetite has a potential for producing a magnetic field that is three times larger than the Earth's magnetic field. The direction of induced magnetization is parallel to the present geomagnetic field, assuming an isotopic susceptibility, and the ratio of the amplitudes of the vertical component to the horizontal component produced by induced magnetization should be about 1.2 at Site 865 . Horizontal magnetic fields are possibly affected by the tool rotation. This implies that the amplitudes of the sharp increases in the horizontal component are almost the same as the amplitudes of the sharp increase in the vertical component.

In contrast to the ordinary drill pipe, the magnetization of the BHA may be affected by a permanent magnetization. Apparent inclination within the BHA is $22.2^{\circ}$, which is somewhat shallower than that of the present magnetic field at Site 865 . This shows that the main source of the magnetization is possibly an induced magnetization. However, magnetization of each part of the BHA produces magnetic-field variations in spite of the same inner and outer diameter of each part of the $\mathrm{BHA}$; thus, heterogeneous magnetization of the component parts is suggested. A completely saturated magnetic-field variation of the vertical component in a downward direction was recorded at about 1500 mbrf within the BHA; corresponding magnetic-field variations in the horizontal component were not observed. This suggests a negative inclination for part of the BHA that cannot be explained by an induced magnetization. These observations imply a contribution of permanent magnetization within the BHA.
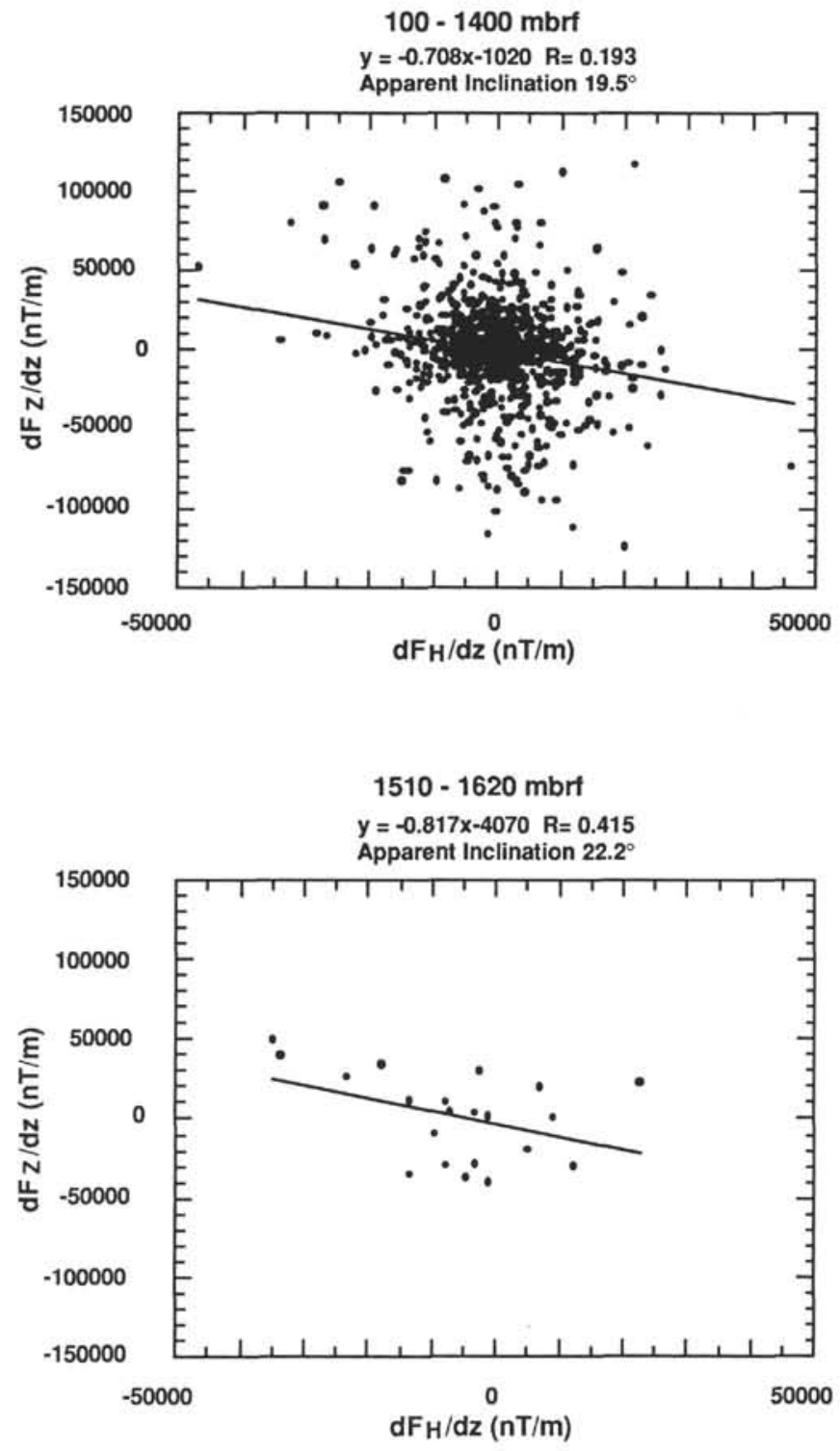

Figure 5. Correlation between the horizontal and vertical component spatial differentials between 100 and 1400 mbrf in the drill pipe, and between 1510 and $1620 \mathrm{mbrf}$ in the BHA. Regression line, equation, and apparent inclination value are also shown.

The strong permanent magnetization of the drill pipe between 344 and 356 mbrf should be considered. The completely saturated variation of the vertical component in a downward direction was observed within two pipes between 344 and $356 \mathrm{mbsf}$, but there was no significant change in the horizontal component of the magnetic field. This variation suggests a steep negative inclination in magnetization of the drill pipes, implying a significant contribution of a permanent magnetization. Amplitudes of these magnetic variations cannot be estimated because of the broad width of the saturated zone. However, considerable high amplitudes of the vertical magnetic field in a downward direction are expected.

The magnetization of most the drill pipe does not seem adequate to cause secondary magnetizations in core samples. In general, amplitudes of magnetic-field variations in almost all the drill pipe are only two or three times larger than those of the Earth's magnetic field, and those in the BHAs are about five times larger. Such amplitudes are probably too small to affect the magnetizations of most core 
samples. Permanent magnetization of some pipes, however, as observed between 344 and 346 mbrf and some segments of BHA, possibly, has the potential for contributing secondary magnetization to core samples.

The ship's magnetization and the well head are considered to be the other possible sources for contributing secondary magnetization to core samples. Although the ship's magnetization appears to be high, as observed above $20 \mathrm{mbrf}$, the nature of its magnetization is unclear. If the most of the drill pipe is not the cause for the secondary magnetizations seen in core samples, and only some drill pipes and part of the BHA are the cause, then it should be possible to detect them and prohibit their use.

\section{CONCLUSIONS}

Sharp negative peaks in the vertical magnetic field and sharp positive spikes in the horizontal component were observed with a regular $10-\mathrm{m}$ spacing within the drill string at Site 865 . This interval nearly coincides with the length of one joint of drill pipe $(9.65 \mathrm{~m})$. Induced magnetizations appear to be the source. Magnetic-field variations from a model calculation using a simple configuration of drill pipe are in good agreement with those observed. Induced magnetization by the thick parts (at either end) of a joint of drill pipe causes magnetic-field variations. Induced magnetization also appears predominant in the BHA, but it is also affected somewhat by a permanent magnetization. The maximum amplitude of magnetic-field variations in almost all of the drill pipe is two or three times larger than that of the Earth's magnetic field, and that in the BHA is about five times larger. Such amplitudes seem unlikely to cause secondary magnetizations of paleomagnetic core samples. However, stronger permanent magnetizations of the pipe between 344 and 356 mbrf and some segments of the BHA are suggested. This strong permanent component of magnetization is a likely cause of secondary magnetization, suggesting that previously reported overprints in paleomagnetic studies have very local sources.

\section{ACKNOWLEDGMENTS}

Y.N. thanks C. Itota for discussions. We also thank N. Niitsuma and anonymous reviewer for their reviews and helpful comments. The Japanese downhole three-component magnetometer was developed and fabricated by Meisei Electronic Co., Inc. The magnetometer was calibrated at Kakioka Magnetic Observatory. Y.N. is grateful to the members of the Geochemical Research Department, Meteorological Research Institute, for their understanding and interest in our observations. We thank the Ocean Research Institute, University of Tokyo, and the Ocean Drilling Program for the opportunity of participating in Leg 143.

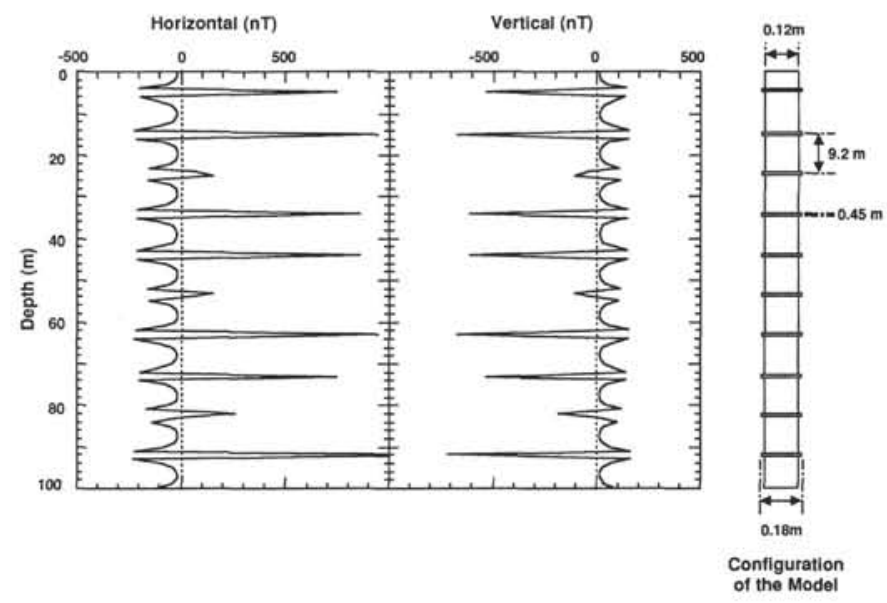

Figure 6. Magnetic-field variations of the horizontal and vertical components from a simple model of the drill string using cylindrical, homogeneous magnetized bodies. Configuration of the model is based on drill pipe and its component joints. Magnetization is assumed to have normal magnetization in the Northern Hemisphere, with an intensity of $20 \mathrm{~A} / \mathrm{m}$ and an inclination of $19.5^{\circ}$.

\section{REFERENCES*}

Dunlop, D.J., 1986. Hysteresis properties of magnetite and their dependence on particle size: a test of pseudo-single-domain remanence models. $J$. Geophys. Res., 91:9569-9584.

Hamano, Y., and Kinoshita, H., 1990. Magnetization of the oceanic crust inferred from magnetic logging in Hole 395A. In Detrick, R., Honnorez, J., Bryan, W.B., Juteau, T., et al., Proc. ODP, Sci. Results, 106/109: College Station, TX (Ocean Drilling Program), 223-229.

Kikawa, E., and Pariso, J.E., 1991. Magnetic properties of gabbros from Hole 735B, Southwest Indian Ridge. In Von Herzen, R.P., Robinson, P.T., et al., Proc. ODP, Sci. Results, 118: College Station, TX (Ocean Drilling Program), 285-307.

\footnotetext{
Abbreviations for names of organizations and publications in ODP reference lists follow the style given in Chemical Abstracts Service Source Index (published by American Chemical Society)
}

Date of initial receipt: 1 December 1993

Date of acceptance: 23 May 1994

Ms 143SR-240 